\title{
The Making of Flash Card and Augmented Reality-Based Application as a Learning Media for Special Needs Children
}

\author{
Robby Kurniawan Budhi ${ }^{1}$, Agus Prayitno ${ }^{2}$, Reyner Ricardo ${ }^{3}$, Ong Peter Leonardo ${ }^{4}$ \\ ${ }^{1}$ Fakultas Teknik Universitas Widya Kartika \\ Surabaya, Indonesia, e-mail: robby@widyakartika.ac.id \\ ${ }^{2}$ Fakultas Teknik Universitas Widya Kartika \\ Surabaya, Indonesia, e-mail: agusprayitno@widyakartika.ac.id \\ ${ }^{3}$ Fakultas Teknik Universitas Widya Kartika \\ Surabaya, Indonesia, e-mail: reynerricardo94@gmail.com \\ ${ }^{4}$ Fakultas Sastra dan Pendidikan Bahasa Universitas Widya Kartika \\ Surabaya, Indonesia, e-mail: peterleonardo@widyakartika.ac.id
}

\section{ARTICLE INFO}

Article history:

Received 28 September 2018

Received in revised form 26 Oktober 2018

Accepted 30 November 2018

Available online 31 Januari 2019

\begin{abstract}
This study aims to measure the level of effectiveness of the use of flash cards and applications based on Augmented Reality as a learning aid. The use of Android applications and AR cards that can also function as flash cards has proven to attract interest and increase student motivation in learning. Number recognition material and addition of unit numbers are chosen as the initial experiment stage which aims to introduce the use of assistive devices in the form of tablet PCs or smartphones to the children. Based on the results of the study, both teachers and students felt helped by the existence of this application as a variety of learning media. The research method used in this study is Multiple Baseline Design Across Subjects, while the sampling technique used is census sampling technique.
\end{abstract}

Keywords: augmented reality, flash card, learning media, special needs children

\section{Pendahuluan}

Menurut hasil survey yang telah dilakukan pada Sekolah Luar Biasa (SLB) Aditama, sekolah menyediakan 1 guru pada tiap kelas untuk mengajari 2 - 4 murid secara privat dalam segala hal mata pelajaran termasuk pelajaran matematika. Setiap murid berkebutuhan khusus yang berada pada sekolah tersebut untuk dapat mengenali jumlah suatu barang, mereka harus mendapatkan pengajaran mengenai pengenalan benda dan angka terlebih dahulu, karena bila mereka dihadapkan pada suatu benda, dan ditanya berapa jumlahnya, maka mereka akan menjawab nama benda tersebut dan bukan jumlah dari barang tersebut. Adapun dalam proses penambahan serta pengurangan juga tidak dapat dilakukan secara serentak. Siswa digolongkan sesuai dengan kemampuan masing - masing, berikutnya siswa diajarkan materi pelajaran matematika mengenal benda dan angka setelah itu siswa diajarkan mengenai penjumlahan dan pengurangan satu digit angka.

Kurikulum pada SLB Aditama menerapkan kurikulum terbaru yaitu kulikulum 2013 (K13) dimana materi pelajaran pada kurikulum ini disesuaikan agar dapat mengarahkan siswa berdasarkan kebutuhannya. Dalam dunia pendidikan saat ini, semua orang berhak mendapatkan pendidikan yang memadai termasuk untuk anak berkebutuhan khusus (ABK) yang memiliki karakteristik khusus yang berbeda dengan anak pada umumnya. Karena karakteristik dan 
hambatan yang dimiliki, anak berkebutuhan khusus memerlukan bentuk pelayanan pendidikan khusus yang disesuaikan dengan kemampuan dan potensi mereka [1]. Mereka memerlukan layanan yang bersifat khusus dalam pendidikan, agar hambatan belajarnya dapat diperkecil sehingga kebutuhannya dapat dipenuhi. Pemerintah saaat ini telah memberikan dukungan dan pengembangan bagi pendidikan inklusi khususnya dengan pendirian SLB [2], namun fasilitas yang tersedia terutama fasilitas pembelajaran dirasa masih sangat kurang. Kurikulum yang digunakan untuk SLB juga hanya merupakan adaptasi dari kurikulum 2013 yang sudah ada, namun tidak secara spresifik untuk Pendidikan Luar Biasa (PLB) [3].

Selama ini proses pembelajaran masih banyak menggunakan buku atau modul khususnya bagi anak berkebutuhan khusus. Hal ini seharusnya menuntut para pengembang teknologi untuk membuat aplikasi - aplikasi baru yang bertujuan untuk dapat lebih memudahkan dalam memahami informasi yang diberikan oleh pengajar, dan akan sangar menarik bila teknologi yang sedang berkembang dapat dimanfaatkan di dunia pendidikan baik secara formal maupun informal. Terlebih lagi apabila diterapkan untuk aplikasi berjenis multimedia, yang mana dapat memberikan suatu informasi yang mudah dipahami sehingga akan lebih mudah dalam memahami informasi pembelajaran matematika yang dibutuhkan. Teknologi yang sedang berkembang saat ini adalah Augmented Reality (AR) yang merupakan teknologi yang menggabungkan dunia nyata dengan dunia maya, yang memungkinkan obyek di dunia maya ditampilkan dengan obyek di dunia nyata secara bersamaan sehingga memungkinkan pengembangan aplikasi ini dalam berbagai bidang, termasuk dalam bidang pendidikan[4].

Penelitian yang dilakukan oleh Nazaruddin menyatakan bahwa AR dapat digunakan untuk pembelajaran bagi anak autisme [5]. Pada penelitian ini, ABK yang diteliti adalah anak dengan tuna grahita (gangguan kecerdasan dan tingkat adaptasi terhadap lingkungan sekitar), sebagai pengembangan dari subjek sebelumnya yang hanya meneliti anak autisme. Sedangkan metode penerapan teknologi yang digunakan dalam penelitian ini adalah multiple baseline design across subjects [6] karena menggunakan sample penelitian yang memiliki kondisi awal (usia dan tingkat pendidikan) yang berbeda. Materi awal yang diterapkan adalah perhitungan matematika sederhana karena dianggap lebih relevan untuk tingkat pendidikan yang heterogen.

Penelitian ini bertujuan untuk memberikan alternatif dan pengayaan media pembelajaran berbasis multimedia. Melalui penggunaan teknologi Augmented Reality dalam aplikasi ini, diberikan fitur - fitur yang mendukung hal - hal yang berkaitan dengan penyampaian informasi untuk mengajarkan penjumlahan dan pengurangan satu digit tentu akan menjadi hal yang baru, yang diharapkan dapat membantu proses belajar. Selain itu dalam penelitian ini juga diteliti mengenai respon dari anak berkebutuhan khusus terhadap penggunaan teknologi berbasis Augmented Reality.

\section{Metode Penelitian}

\subsection{Langkah Penelitian}

Langkah pelaksanaan ini berisi penjelasan mengenai langkah-langkah yang digunakan dalam melakukan penelitian ini yang meliputi :

a. Pengumpulan Data: berupa isi materi teori - teori matematika dasar penjumlahan dan pengurangan yang diambil dari buku cetak, dan kurikulum yang dipakai oleh SLB. Sedangkan flash card dan gambar kartu dibuat menggunakan software CorelDraw.

b. Analisa Kebutuhan Pengguna dan Merancang Desain Sistem: Data yang telah dikumpulkan dianalisa sesuai dengan kebutuhan pengguna dan kemudian hasil dari analisa tersebut akan dibuat rancangan desain yang akan diterapkan pada aplikasi yang akan dibuat.

c. Pembentukan Aplikasi dan Marker: Pembentukan Aplikasi dan Marker mengikuti rancangan desain sistem yang telah dibuat dengan menggunakan flowchart dan UML untuk memudahkan dalam proses pembuatan aplikasi. Marker juga berfungsi sebagai flash card yang dapat digunakan terpisah dari aplikasi. 
d. Uji Coba dan Evaluasi: Aplikasi yang telah selesai dibuat kemudian dilakukan ujicoba lapangan kepada para murid SLB dan guru Aditama, untuk mengetahui apakah aplikasi yang telah dirancang telah sesuai dengan kebutuhan pengguna atau belum, kemudian dilakukan evaluasi terhadap aplikasi dengan meminta guru untuk mengisi kuesioner dan memberi saran serta masukkan untuk aplikasi.

e. Penarikan Kesimpulan: Langkah terakhir adalah pengambilan kesimpulan berdasarkan hasil analisa data yang telah didapatkan selama penelitian.

\subsection{Metode Pengumpulan Data}

Data yang diperoleh pada penelitian ini dikumpulkan melalui berbagai cara yaitu pengamatan langsung di lapangan, survey kepada responden, wawancara kepada pihak terkait, dan studi literatur. Data-data tersebut kemudian dianalisa dan diolah secara statistik untuk mengambil kesimpulan.

\subsection{Jenis Data}

Data yang diolah dalam penelitian ini merupakan data kuantitatif dan kualitatif. Data kuantitatif yaitu hasil pre-test dan post-test dari siswa yang dijadikan sampel penelitian. Sedangkan data kualitatif berupa hasil observasi siswa serta wawancara yang dilakukan terhadap guru. Terdapat beberapa data yang diamati dalam penelitian ini yaitu:

a. Tingkat pemahaman siswa. Data yang terukur melalui hasil pre-test dan post-test evaluasi berupa soal penjumlahan dan pengurangan yang dikerjakan oleh siswa, sebelum dan sesudah menggunakan aplikasi.

b. Kecepatan siswa memahami dan mengerjakan soal evaluasi. Kecepatan siswa juga dibandingkan antara sebelum dan sesudah treatment.

c. Perbandingan antusiasme siswa. Hal ini didapatkan melalui observasi dan wawancara dengan guru.

\subsection{Metode Analisis Data}

Pemrosesan data untuk analisa dilakukan secara interaktif mulai dari pengumpulan data hingga pengambilan kesimpulan. Tahapan metode yang dilakukan adalah sebagai berikut[7].

a. Reduksi data, dengan merangkum dan segmentasi data yang diperlukan. Data hasil observasi ataupun pre test dan post test dibandingkan dengan hasil wawancara.

b. Display data, penyajian dalam bentuk bagan dan uraian singkat. Adapun teknik analisa data menggunakan t-test Paired Two Samples for Means [8].

c. Pengambilan kesimpulan berdasarkan hasil analisa data yang diperoleh.

\subsection{Metode Pengembangan Sistem}

Tahapan pengembangan aplikasi yang dibuat di dalam penelitian ini adalah sebagai berikut:

1. Pengumpulan data, yang didapatkan melalui teknik pengumpulan data yang telah disebutkan sebelumnya

2. Analisa kebutuhan sistem, berupa pengolahan data yang telah didapatkan di awal sebagai acuan pengembangan sistem selanjutnya

3. Perancangan sistem, yaitu pembuatan desain sistem yang disesuaikan dengan kebutuhan pengguna

4. Implementasi sistem, berupa penterjemahan desain menjadi aplikasi berbasis Augmented Reality

5. Uji coba sistem, untuk mengukur respon pengguna serta mengetahui kemungkinan terjadinya kesalahan dalam aplikasi

6. Evaluasi sistem, berupa analisis hasil uji coba yang digunakan untuk tahap pengembangan lebih lanjut. 


\section{Hasil dan Pembahasan}

\subsection{Analisa Kondisi Awal Objek Penelitian}

Pengamatan awal yang dilakukan terhadap siswa SLB Aditama selama 3 hari secara berurutan. Hal ini dilakukan untuk mengetahui data awal kemampuan siswa dalam penguasaan materi berhitung secara konvensional, sebelum penerapan teknologi menggunakan aplikasi AR. Pre-test dan wawancara dilakukan terhadap guru pengajar agar tidak mengganggu proses pembelajaran, karena siswa biasanya terganggu dengan adanya pihak yang asing dan belum dikenal.

Berdasarkan pengamatan tersebut, terindikasi masalah yang dihadapi dalam proses pembelajaran yaitu penggunaan kurikulum yang sama dengan sekolah umum, demikian juga untuk buku ajar yang kurang mampu memenuhi kebutuhan siswa. Oleh sebab itu pada sekolah ini, siswa dikelompokkan berdasarkan penguasaan materi, bukan umur atau kelas. Tingkat penguasaan diukur melalui soal penjumlahan dan pengurangan bilangan satuan. Hasilnya, rerata penguasaan materi mencapai $60 \%$ dan soal penjumlahan lebih tinggi penguasaannya dibandingkan soal pengurangan.

\subsection{Proses Pengembangan Aplikasi dan Flash Card}

A. Alur Kerja Aplikasi

Berdasarkan hasil pengamatan, maka disusun kerangka alur aplikasi yang dapat digambarkan melalui bagan alir pada Gambar 1 berikut.

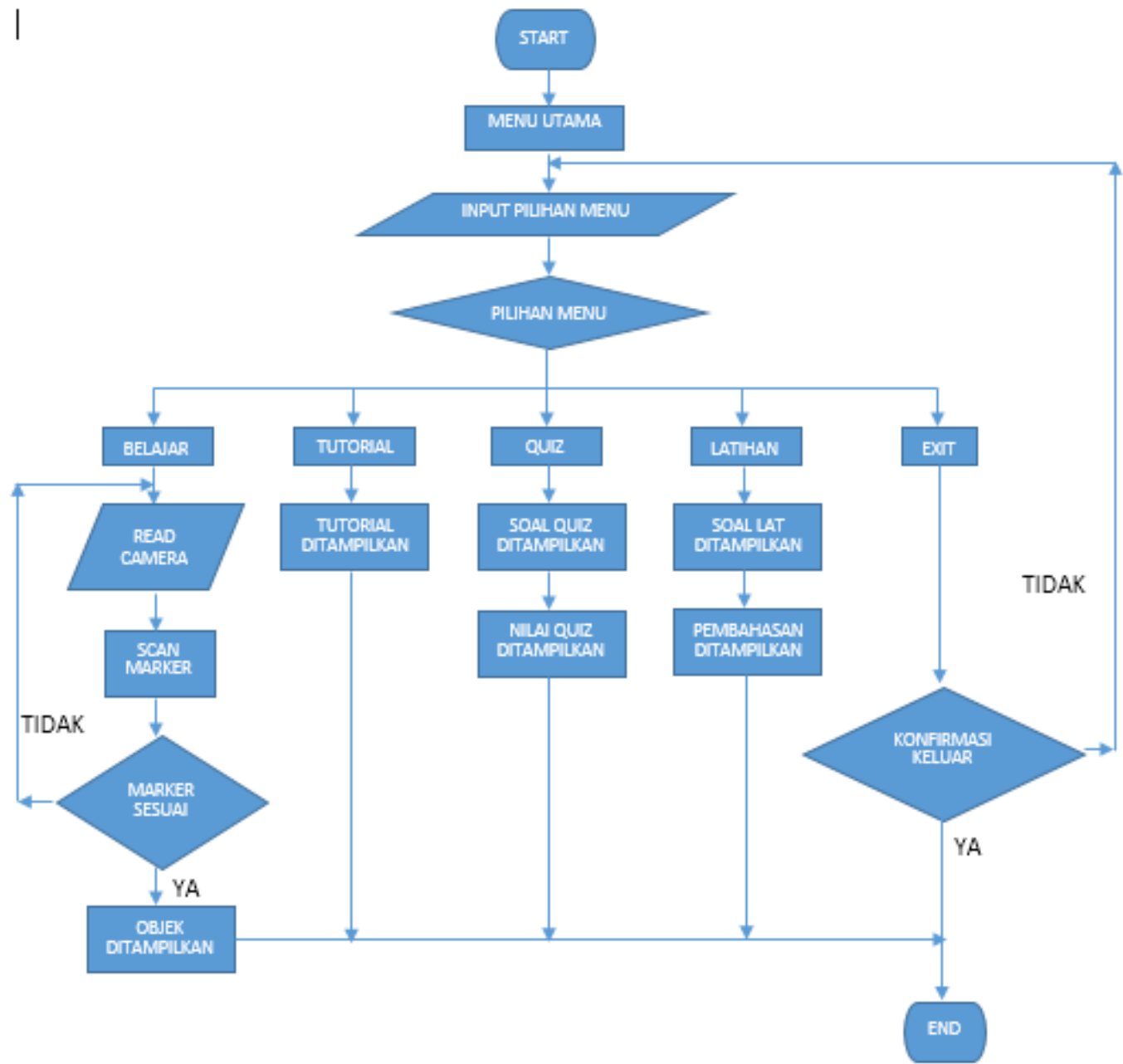

Gambar 1. Bagan alir aplikasi

Terdapat pembagian menu menjadi beberapa kelompok yaitu:

1. Menu "belajar", digunakan untuk menampilkan realita tambahan yang digunakan bersama dengan flash card sebagai marker. 
2. Menu "tutorial", menampilkan cara penggunaan aplikasi.

3. Menu "quiz", merupakan bagian yang digunakan untuk mengukur kemampuan siswa dalam mengerjakan soal, dan akan menghitung jumlah soal yang berhasil dikerjakan dengan benar oleh siswa.

4. Menu "latihan", digunakan untuk berlatih soal disertai dengan jawaban yang benar saat siswa telah memberikan jawaban.

B. Desain Tampilan Aplikasi dan Flash Card sebagai Marker

Penggunaan aplikasi augmented reality membutuhkan marker sebagai pemicu tampilan. Pada penelitian ini, flash card dibuat sebagai marker. Terdapat dua jenis objek yang ditampilkan sebagai marker. Karena pembelajaran yang diberikan berfokus pada pengenalan angka, penjumlahan bilangan, dan pengurangan bilangan satuan, maka objek pertama adalah tampilan angka mulai dari 0 (nol) sampai 9 (sembilan). Sedangkan objek kedua yang ditampilkan adalah berupa gambar buah apel dengan jumlah mulai dari 1 (satu) sampai 9 (sembilan). Gambar apel dipilih sebagai objek karena buah tersebut sudah dikenal secara umum. Beberapa contoh desain kartu dapat dilihat pada gambar 2 berikut.

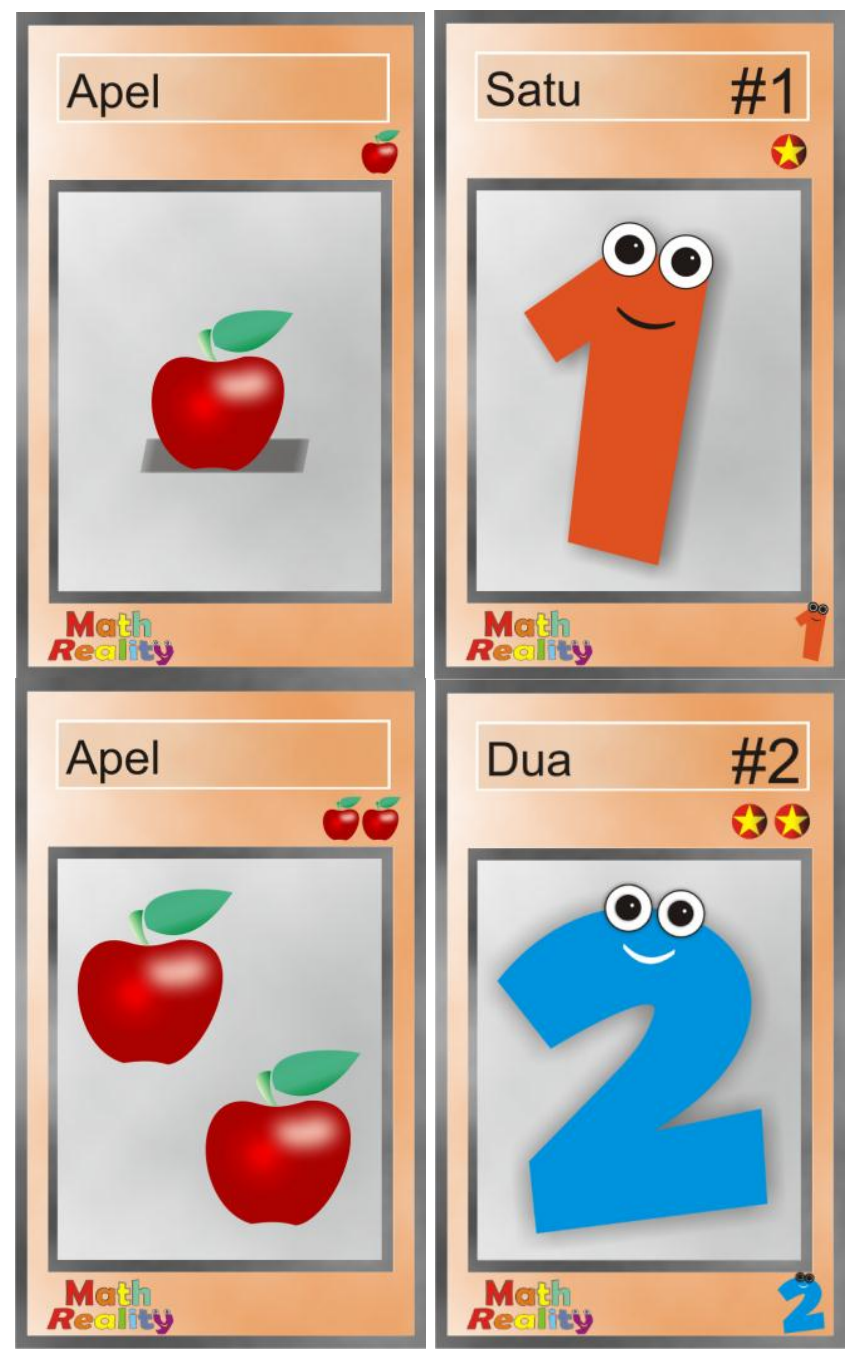

Gambar 2. Desain marker sekaligus flash card

Flash card ini membutuhkan beberapa titik sebagai acuan marker agar dikenali dengan baik oleh aplikasi AR. Selain gambar objek apel atau bilangan yang terdapat di bagian tengah kartu, diberikan juga gambar apel yang berukuran lebih kecil sejumlah bilangan yang ditunjukkan. Fungsi gambar tersebut juga sebagai penanda (marker). Pada objek berupa angka, dimunculkan 
gambar bintang yang berukuran kecil sejumlah bilangan yang ditunjuk. Fungsinya sama dengan gambar apel kecil yang sudah dijelaskan sebelumnya. Penggunaan nama Math Reality didasarkan pada materi matematika yang diajarkan menggunakan augmented reality. Gambar 3 berikut menunjukkan hasil tampilan kartu saat menggunakan augmented reality.

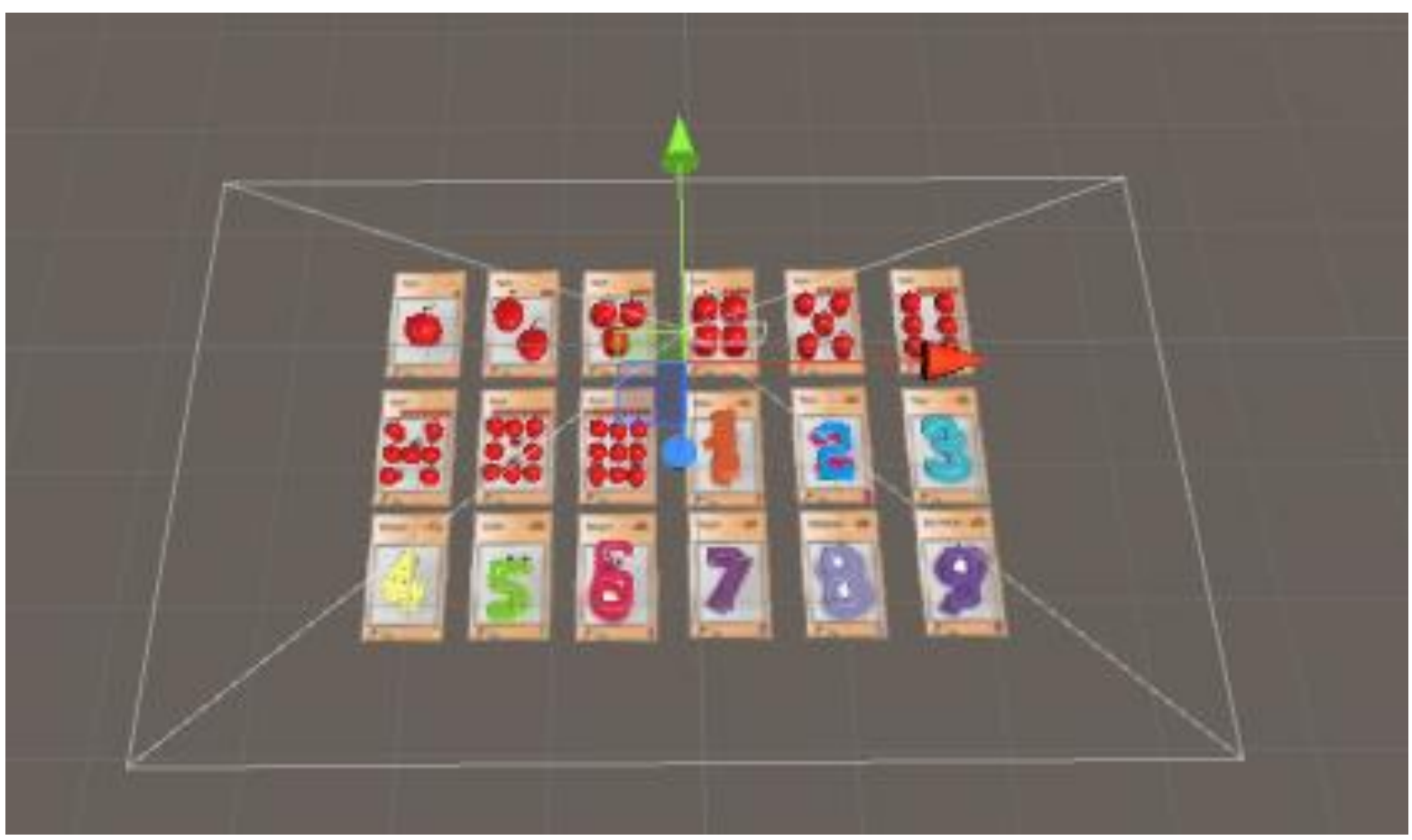

Gambar 3. Hasil tampilan kartu menggunakan augmented reality

Tampilan awal aplikasi menampilkan menu sesuai dengan diagram alir yang telah dirancang. Terdapat beberapa menu yaitu "belajar", "latihan", "quiz", "tutorial", dan tombol "exit" untuk menutup aplikasi seperti pada gambar 4 berikut.

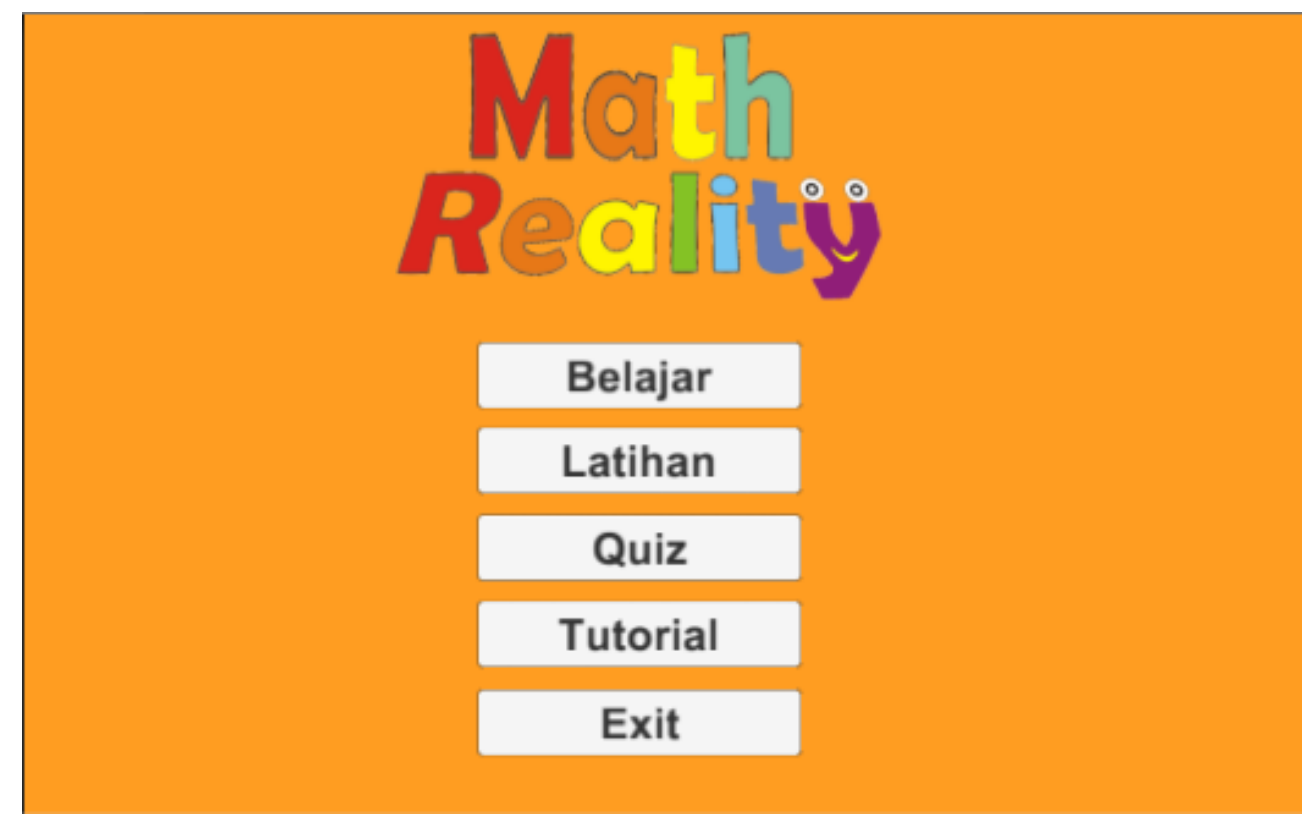

Gambar 4. Tampilan menu aplikasi 


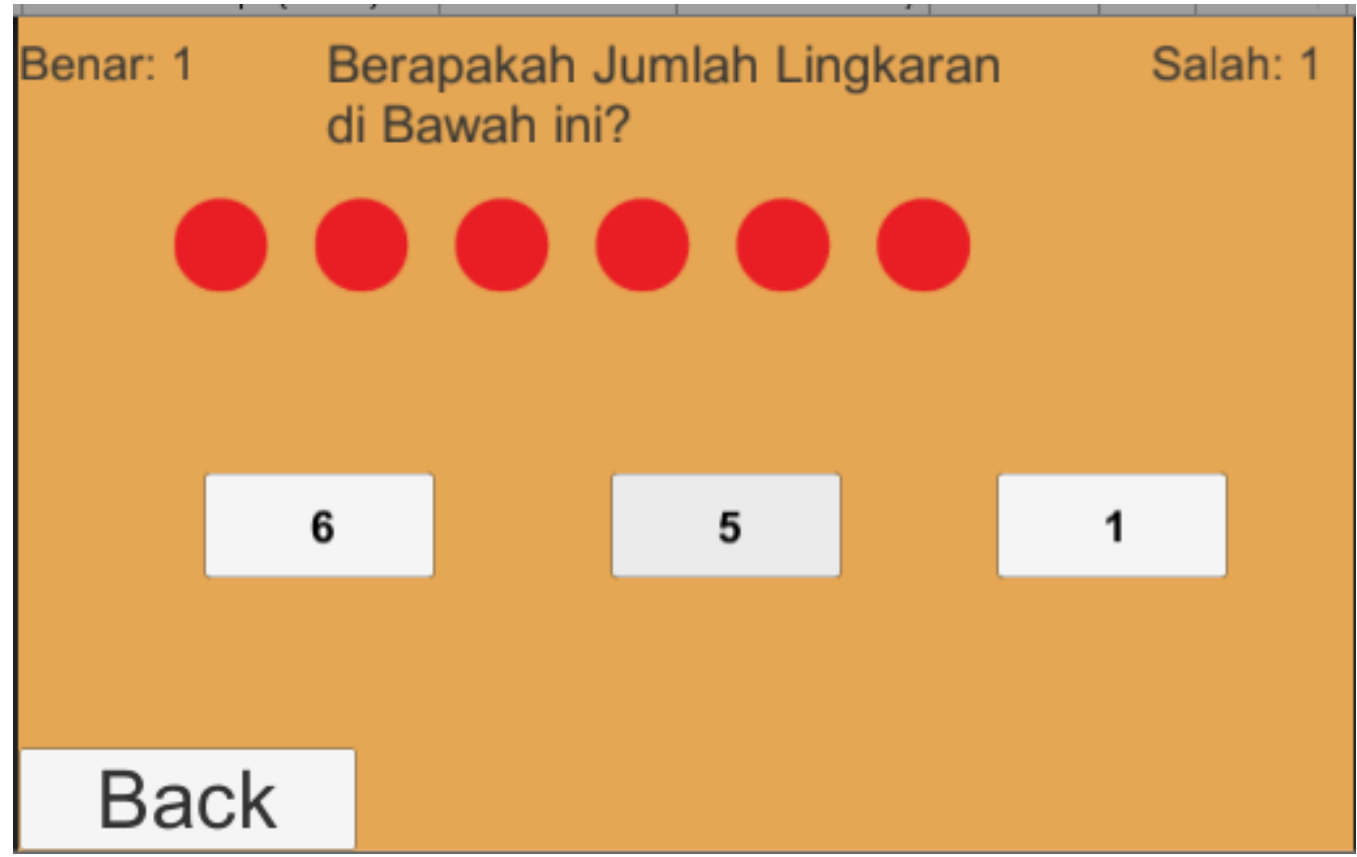

Gambar 5. Tampilan soal dalam menu "quiz"

Gambar 5 menunjukkan tampilan contoh soal dalam menu "quiz" yang digunakan siswa untuk mengukur hasil pembelajaran. Disediakan beberapa pilihan jawaban berupa tombol yang dapat dipilih untuk menjawab soal penjumlahan dan pengurangan yang diberikan. Ditampilkan pula jumlah jawaban salah dari soal yang telah dikerjakan.

\subsection{Data Hasil Penerapan Treatment}

Setelah penerapan penggunaan aplikasi terdapat perbedaan yang cukup signifikan. Penggunaan tablet PC sebagai alat bantu, terbukti efektif untuk meningkatkan minat dan mempersingkat waktu penguasaan materi pembelajaran. Hal tersebut sesuai dengan hasil penelitian lain yang dilakukan oleh Lorah [10] dan Kagohara [11].

Guru juga merasa terbantu dan dapat lebih mudah menjelaskan materi kepada siswanya sehingga waktu pembelajaran juga lebih efektif dan singkat. Hal yang sangat terlihat adalah meningkatnya antusiasme siswa dalam mempelajari materi. Berdasarkan hasil post test yang diberikan, hal tersebut juga dapat terukur dengan baik.

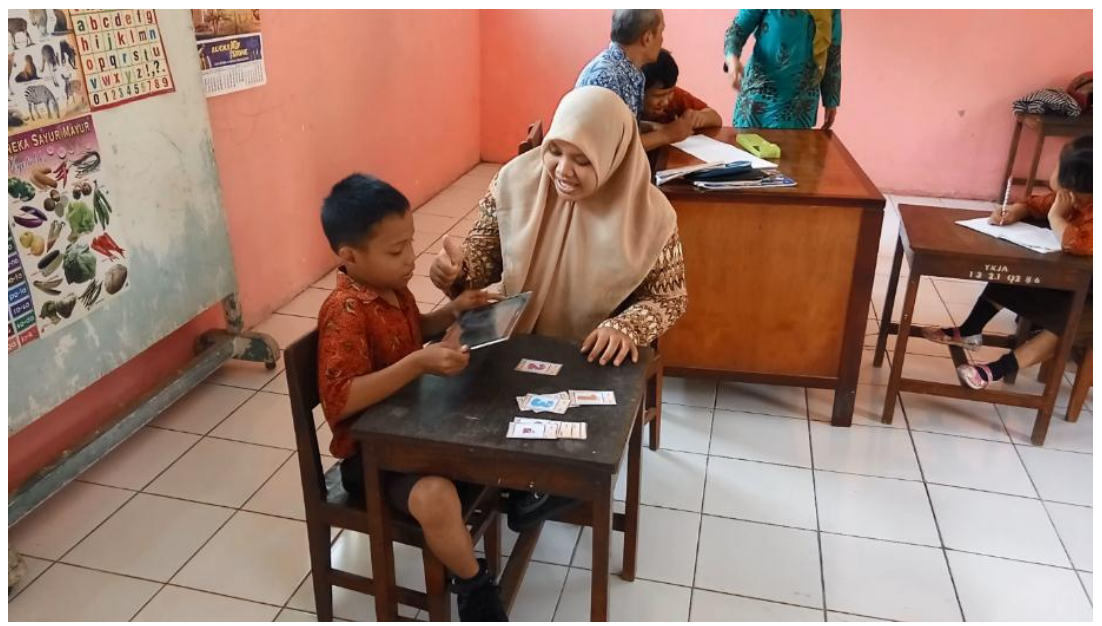

Gambar 6. Uji coba pembelajaran 
Berikut adalah data hasil perbandingan evaluasi soal penjumlahan, pengurangan, beserta waktu pengerjaan yang ditampilkan pada Tabel 1 berikut ini.

Tabel 1. Hasil Pengukuran Pengerjaan Soal Evaluasi oleh Siswa

\begin{tabular}{|c|c|l|l|l|l|l|l|l|}
\hline \multirow{2}{*}{ Siswa } & \multicolumn{3}{|c|}{ Sebelum Treatment } & \multicolumn{4}{c|}{ Sesudah Treatment } \\
\cline { 2 - 9 } & $(+)^{\boldsymbol{a}}$ & $(-)^{\boldsymbol{b}}$ & $\boldsymbol{J m l}^{\boldsymbol{c}}$ & Waktu $^{\boldsymbol{d}}$ & $(+)$ & $(-)$ & Jml & Waktu \\
\hline A & 5 & 4 & 9 & 15 & 5 & 5 & 10 & 12 \\
\hline B & 3 & 2 & 5 & 19 & 3 & 3 & 6 & 20 \\
\hline C & 4 & 4 & 8 & 18 & 4 & 4 & 8 & 16 \\
\hline D & 5 & 3 & 8 & 16 & 5 & 4 & 9 & 15 \\
\hline E & 2 & 2 & 4 & 20 & 3 & 3 & 6 & 22 \\
\hline F & 3 & 3 & 6 & 18 & 4 & 3 & 7 & 17 \\
\hline G & 5 & 3 & 8 & 15 & 5 & 5 & 10 & 12 \\
\hline H & 4 & 5 & 9 & 15 & 5 & 5 & 10 & 15 \\
\hline I & 2 & 1 & 3 & 20 & 3 & 2 & 5 & 15 \\
\hline J & 3 & 2 & 5 & 18 & 4 & 3 & 7 & 19 \\
\hline Rerata & 3,6 & 2,9 & 6,5 & 17,4 & 4,1 & 3,7 & 7,8 & 16,3 \\
\hline
\end{tabular}

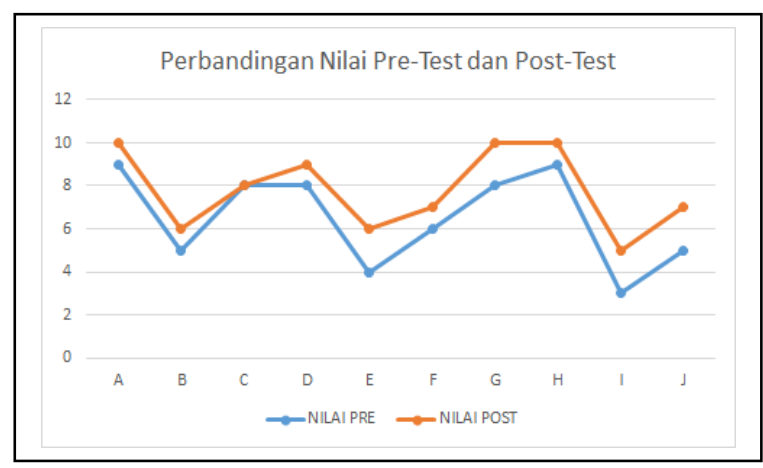

Gambar 7. Grafik Nilai Pre Test dan Post Test

Analisa t-test digunakan untuk pengujian efektifitas penggunaan aplikasi seperti yang ditampilkan pada tabel 2 berikut ini.

Tabel 2. Hasil Analisa T-Test

\begin{tabular}{|l|r|r|}
\hline & \multicolumn{1}{|c|}{ Pre-Test } & \multicolumn{1}{|c|}{ Post-Test } \\
\hline Mean & 6,5 & 7,8 \\
\hline Variance & 4,72222222 & 3,511111111 \\
\hline Observations & 10 & 10 \\
\hline Pearson Correlation & 0,95505864 & \\
\hline Hypothesized Mean Difference & 9 & \\
\hline df & 9 & \\
\hline t Stat & $-6,090776714$ & \\
\hline P(T<=t) one-tail & $9,06314 \mathrm{E}-05$ & \\
\hline t Critical one-tail & 1,833112933 & \\
\hline P(T<=t) two-tail & 0,000181263 & \\
\hline t Critical two-tail & 2,262157163 & \\
\hline
\end{tabular}


Tabel 2 tersebut menunjukkan bahwa t tabel bernilai 1,833112933 dan t hitung bernilai 6,090776714 . Hal tersebut mengindikasikan perbedaan signifikan antara sebelum dan sesudah penerapan aplikasi. Nilai probabilitas, P-value sebesar 9,06314E-05 lebih kecil dari 0,05 yang berarti penerapan dinilai efektif.

\section{Kesimpulan}

Kesimpulan yang didapatkan melalui penelitian ini adalah sebegai berikut:

a. Metode dan media pembelajaran harus disesuaikan dengan kebutuhan siswa, terutama untuk anak berkebutuhan khusus (ABK) yang sangat berbeda dengan pembelajaran pada umumnya.

b. Kurikulum Pendidikan Luar Biasa (PLB) secara khusus diperlukan, dan tidak sama dengan kurikulum umum.

c. Aplikasi berbasis Augmented Reality memberi hasil yang signifikan bagi ABK di SLB Aditama terutama dalam materi berhitung.

d. Aplikasi ini cocok digunakan bagi anak tunagrahita karena dapat membantu peningkatan daya ingat.

e. Penggunaan aplikasi lebih baik juga dapat dimanfaatkan oleh wali murid.

\section{Acknowledgement}

Penelitian ini didanai oleh Kementrian Riset, Teknologi, dan Pendidikan Tinggi melalui skema Hibah Penelitian Dosen Pemula tahun pelaksanaan 2018.

\section{References}

[1] W.L. Heward and C.L. Wood, EXCEPTIONAL CHILDREN: An introduction to special education. Upper Saddle River: Pearson, 2018

[2] D. Maulipaksi, "Sekolah Inklusi dan Pembangunan SLB Dukung Pendidikan Inklusi", Kementerian Pendidikan dan Kebudayaan, 01-Feb-2017. [Online]. Available: https://www.kemdikbud.go.id/main/blog/2017/02/sekolah-inklusi-danpembangunan-slb-dukung-pendidikan-inklusi. [Accessed: 28-Jun-2018].

[3] A. Marani, "Kurikulum Bagi Anak Berkebutuhan Khusus (ABK)”, Jurnal Studia Insania, vol. 5, no. 2, pp. 105-119, Nov. 2017.

[4] R. van Krevelen and R. Poelman, "A Survey of Augmented Reality Technologies, Applications and Limitations", International Journal of Virtual Reality, vol. 9, no. 2, pp. 1-21, 2010.

[5] M.A. Nazaruddin and M. Efendi, "The Book of Pop Up Augmented Reality to Increase Focus and Object Recognition Capabilities for Children with Autism", Journal of ICSAR, vol. 2, no. 1, pp. 9-14, Jan 2018.

[6] C. Botella, R. M. Baños, H. Villa, C. Perpiñá, and A. García-Palacios, "Virtual reality in the treatment of claustrophobic fear: A controlled, multiple-baseline design", Behavior Therapy, vol. 31, no. 3, pp. 583-595, 2000.

[7] M. B. Miles and A. M. Huberman, Qualitative data analysis a sourcebook of new methods. Newbury Park: SAGE Publ., 1991.

[8] I. Thoifah, Statistika pendidikan dan metode penelitian kuantitatif. Malang: Madani, 2015

[9] R. Erbey, T. F. McLaughlin, K. M. Derby, and M. Everson, "The effects of using flashcards with reading racetrack to teach letter sounds, sight words, and math facts to elementary students with learning disabilities", International Electronic Journal of Elementary Education, vol. 3, no. 3, pp. 213-226, Aug 2017.

[10] E. R. Lorah, A. Parnell, P. S. Whitby, and D. Hantula, “A Systematic Review of Tablet Computers and Portable Media Players as Speech Generating Devices for Individuals with Autism Spectrum Disorder", Journal of Autism and Developmental Disorders, vol. 45, no. 12, pp. 3792-3804, Dec. 2014.

[11] D. M. Kagohara, L. V. D. Meer, S. Ramdoss, M. F. O’Reilly, G. E. Lancioni, T. N. Davis, M. Rispoli, R. Lang, P. B. Marschik, D. Sutherland, V. A. Green, and J. Sigafoos, "Using iPods ${ }^{\circledR}$ and iPads ${ }^{\circledR}$ in teaching programs for individuals with developmental disabilities: A systematic review", Research in Developmental Disabilities, vol. 34, no. 1, pp. 147-156, Jan. 2013. 